\title{
Research on Dynamic Facility Layout Problem of Manufacturing Unit Considering Human Factors
}

\author{
Jinying $\mathrm{Li}^{1},{ }^{1}$ Xin $\operatorname{Tan}\left(\mathbb{D},{ }^{1}\right.$ and Jinchao $\mathrm{Li}^{2}$ \\ ${ }^{1}$ Department of Economics and Management, North China Electric Power University, Baoding 071003, China \\ ${ }^{2}$ School of Economics and Management, North China Electric Power University, Beijing 102206, China \\ Correspondence should be addressed to Xin Tan; tanxin_ie2011@163.com
}

Received 24 August 2017; Revised 6 November 2017; Accepted 14 December 2017; Published 14 January 2018

Academic Editor: Federica Caselli

Copyright (c) 2018 Jinying Li et al. This is an open access article distributed under the Creative Commons Attribution License, which permits unrestricted use, distribution, and reproduction in any medium, provided the original work is properly cited.

\begin{abstract}
As many said, industry 4.0 is an epoch-making revolution which brought the manufacturing market much faster changes and severer competitions. As an important part of the manufacturing system, facility layout has direct impact on business benefit; at the same time, despite the intelligent factory, intelligent production has its own characteristics. However, there is one point on which industry and academia have basically formed a consensus: it is not true that industry 4.0 does not need human beings; on the contrary, human initiative plays an unabated role in the development of industry 4.0. This paper will focus on the dynamic facility layout of the manufacturing unit. Based on the system above and the traditional optimization model, a mathematic model is built to find the best solution combining safety, sustainability, high efficiency, and low cost. And penalty function with adaptive penalty factor and advanced artificial bee colony algorithm is used to solve the constrained model. In the end, by studying few cases, the model is proved to be effective in both efficiency improvement and the implementation of safe and comfort human-machine interaction.
\end{abstract}

\section{Introduction}

After the age of steam, electricity, and information, global division of labor accelerates the flow and configuration of production factors; the change of market trend and the individuation of product propose an unprecedented demand for enterprise response time and flexibility; the world has entered an era of innovation, concentration, and industry transformation. Based on this, industrial 4.0, led by the Internet, cloud computing, big data, Internet of things, and intelligent manufacturing, has quietly struck. With the advent of the industrial 4.0, people are still the core of the manufacturing system, and the defects of the layout design of the manufacturing units will lead to the physical and psychological pressure of the operator and cause a large number of cumulative occupational musculoskeletal injuries and mental illness. "The statistical report of occupational injury and occupational diseases in 2015" the United States issued shows that there were about 2.9 million cases of nonfatal occupational injuries and occupational diseases in private enterprises in the United States, and the incidence rate was 3 per 100 full-time employees in 2015. Thus, a new and feasible scheme for the layout in the factory is required to further solve the facility layout [1].

With the rapid development of economy and technology, a series of new features emerge in the facility layout of modern manufacturing unit. Firstly, since the late 1970s, China's logistics equipment has developed rapidly; some advanced logistics equipment systems are coming forth, such as forklifts, conveyors, automated guided vehicles (AGV), and industrial robots. Secondly, with the advent of the industrial 4.0, many enterprises in China are facing industrial transformation. From the traditional mass production to the present customized products, the production process tends to be flexible and personalized. Thirdly, because of the improvement of people's living standard, the humanity of production has become one of the important directions of future manufacturing unit transformation. Being coupled with the urgent need for innovation in the era of industry 4.0 as well as the increase of labor cost, the damage and psychological pressure of the operators caused by the unreasonable facility are becoming increasingly common [2]. 
Although many people think that industrial 4.0 is a robot factory, improving efficiency and integrating the supply chain are the primary goal of industry 4.0. Traditional unit facility layout optimization design mainly considers whether the logistics are reasonable or not, whether the material handling cost is the lowest or not, whether the pipeline beat is balanced or not, and so on. It ignores human factors in the layout planning and design facilities when ignoring the human factor, because human capacity does not match and the labor intensity of workers is not scientific, affects the production efficiency, and for a long time will cause great damage to the health of workers. However, due to the mismatch of human-machine ability and the unscientific labor intensity of workers, the production efficiency has been greatly affected, and the risk of physical and mental damage to workers has been increasing for a long time. Many scholars begin to attach importance to human factors in the layout of facilities. Rui-Feng et al. (2004) established the evaluation index system of workplace facility layout based on human factors from the aspects of performance measurement, physiological measurement, and subjective measurement, and comprehensively evaluated the logistics factors and human factors in the workplace [3]. Tao et al. (2014), combined with the traditional mathematical model of facility layout, conducted a quantitative analysis of human factors in production operations from the aspects of operator's posture, force strength, job difficulty, and psychological load and established an optimization model of facility layout with logistics and human factors [4]. Huang et al. (2016) [5] chose three different types of communities to evaluate the allocative suitability of community facilities in the three communities in order to meet the requirements of facilities for the elderly. Nevertheless, these facilities layout optimization methods merely consider the operating fatigue level, which needs further study and solution introduces other production factors.

With the rapid development of computer technology, more and more intelligent algorithms are applied to the facility layout problem. Xu and Song (2015) developed adaptive particle swarm optimization (PSO) based on multiobjective location and proposed a new method for solving dynamic temporary construction problems [6]. Matai (2015) proposed an improved simulated annealing (SA) algorithm for solving multiobjective facility layout problems [7]. Ingole and Singh (2016) used the firefly algorithm (FA) to address the problem of layout for unequal area and fixed shape and optimized the total cost of material handling [8]. Next, other algorithms have been applied to deal with facility layout optimization, such as Ant Colony Optimization, the chaos artificial fish swarm algorithm-based coevolutionary, simulated annealing algorithm [9-12].

More and more enterprises begin to pay attention to the facility layout; they set up efficient facilities layout optimization models with some goals, such as minimization of material handling cost [13-17], restructuring cost $[13,16]$, logistics handling distance [18], average WIP [16, 18], number of material handling equipment [18], noise pollution [14], and safety cost [15] and maximization of facility proximity $[13,17]$. After that, the problem of enterprise facility layout has entered a new period.
The following study based on human factor engineering comprehensively considers different factors during the period of layout, including logistics and physical and psychological factors of the workers and management. In order to satisfy the needs of industry 4.0, a model will firstly be built using mathematical programming and then solved with the improved artificial bee colony algorithm.

\section{Materials and Methods}

2.1. Human Factors in Facility Layout. Human factors engineering is the subject which studies human-machine-environment relationship; it mainly studies the physiological and psychological characteristics, the man-machine system, the design of work space, the improvement of working environment, and so on.

From the view of human factors, it is necessary to take into account the efficiency of production and the mental and physical health of the workers at the time of facility layout. That is to say, employees may work at the best productivity while maintaining physical health and psychological pleasure. Scholars have mainly focused on the work posture, human size, the workload, and so on [19-22]. Through the theoretical and empirical research of these scholars, human factors are considered in facility layout; they can improve product quality and production efficiency, reduce production cost, and ensure the physical and psychological health and safety of the operator.

In conclusion, dynamic facility layout problem of manufacturing unit considering human factors must satisfy the following four essential principles [23]:

(1) properly plan human resource allocation, so that the facilities layout can be more in line with the human thinking model and data processing requirements;

(2) improve production efficiency of production line, reduce production cost, and ensure production safety;

(3) optimize the work load and operation posture of workers, minimize the mistakes of people, prevent the occurrence of failures, and establish a healthy, safe, and comfortable working environment for employees;

(4) improve the flexibility of manufacturing facility layout.

2.2. Artificial Bee Colony Algorithm. Artificial bee colony algorithm $(\mathrm{ABC})$ is a novel clustering intelligent optimization algorithm proposed by Karaboga in 2005. The simplicity in calculation and the less control parameters have made the $\mathrm{ABC}$ algorithm become the focus of academic research.

In the $\mathrm{ABC}$ algorithm, the artificial bee contains three components: leader, follower, and scouter. The goal of the whole colony is to find the largest nectar source. The leaders use prior information to find new nectar source and share information with followers; the followers wait in the hive and find the new nectar source based on the information shared by the leaders; the scouters are looking for nectar source at random near the hive. Each source position represents a possible solution to the optimization problem; the amount of nectar corresponds to the fitness of the solution. 
Since the study of $A B C$ algorithm is still in the initial stage, there still exist many problems, such as poor population diversity, slow convergence, and low accuracy, often trapping in local optimum and so on. Some scholars have put forward some improvements, which mainly involve the enhancement of the initial solution, selection strategy, update strategy $[24,25]$, operation mode $[26,27]$, and hybrid algorithm [28]. Because the $A B C$ algorithm is a kind of unconstrained optimization algorithm, some scholars have applied it to the constrained optimization problem $[28,29]$ and multiobjective optimization problem [30-33], for the search strategy formula of basic $\mathrm{ABC}$ algorithm; that is, only one individual and one dimension are selected randomly at each update. This paper uses the evolutionary ideas of particle swarm optimization (PSO), combining with the current location [34], individual best value, and global optimal value, and introduces the linearly decreasing inertia weight. The algorithm has a high global search ability in the early iterations and a more accurate local search ability in the later iterations. At the same time, the bee swarm flies to the optimal solution under the guidance of individual best value and global optimal value. In the improved $\mathrm{ABC}$ algorithm, the search strategy of the leader and the follower is expressed as

$$
\begin{aligned}
x_{i j}^{k+1}= & w x_{i j}^{k}+c_{1} \cdot r_{1}\left(\text { lbest } t_{i j}^{k}-x_{i j}^{k}\right)+c_{2} \\
& \cdot r_{2}\left(\text { gbest }^{k}-x_{i j}^{k}\right),
\end{aligned}
$$

where $w$ is linearly decreasing inertia weight; $i=1,2, \ldots, \mathrm{SN}$; $j=1,2, \ldots, n ; k$ is the current iterative number; $c_{1}$ and $c_{2}$ are learning factor and, respectively, adjust the maximum step length to the global best particle and the individual best particle direction; a large number of experiments show that the algorithm takes the best performance when taking $c_{1}=$ $c_{2}=2 ; r_{1}$ and $r_{2}$ are a random number within $[0,1]$. The expression of linearly decreasing inertia weight is as follows;

$$
\begin{aligned}
& w(k) \\
& =w_{\max } \\
& \quad-\left(w_{\max }-w_{\min }\right)\left(\frac{2 k}{\max C y c l e}-\left(\frac{k}{\max C y c l e}\right)^{2}\right),
\end{aligned}
$$

where $w_{\max }, w_{\min }$ represent the maximum and minimum values of $w$; maxCycle are the largest iterative number. Usually $w_{\max }=0.9, w_{\min }=0.4$.

The selection strategy of traditional $\mathrm{ABC}$ algorithm is using roulette method, but it may produce significant sampling errors; this paper uses multiple roulette selection operators based on sorting. First, all individuals should be sorted from large to small according to their fitness and then selected by roulette method with exponential arithmetic.

$$
p_{i}=\frac{\left(\mathrm{fit}_{i}\right)^{a}}{\sum_{n=1}^{\mathrm{SN}}\left(\mathrm{fit}_{n}\right)^{a}} \quad a>1 .
$$

In this way, individuals with lower fitness can be discarded with greater probability, and the function of random numbers can be more accurately reflected.

\section{Comprehensive Benefit Evaluation Index System of Dynamic Facility Layout Problem of Manufacturing Unit Considering Human Factors}

3.1. Comprehensive Evaluation Index System. On the basis of the four important principles above, this paper mainly evaluates the facilities layout of the workplace from the aspects of logistics factors, human factors, and management factors. First, the logistics is closely related to manufacturing units operating efficiency and thus affects the economic efficiency of enterprises and the future development. Second, the core concept of industrial 4.0 is "people-oriented"; industrial 4.0 transformation and upgrading is not to replace manpower but to put people in the center of the entire production process, to avoid the loss of the core population. In addition, in the industrial 4.0 era, companies are facing more and more global challenges; each consumer can dominate the production of enterprises to provide the product or service suitable for its needs according to their own requirements. Enterprises should be more flexible in dealing with the changes in value chains and new demands of users in a short period of time. The Comprehensive Evaluation Index System of the Workplace layout is listed in Table 1.

\subsection{Analysis of the Comprehensive Evaluation Index}

\subsubsection{Logistics Factors}

(a) The Amount of Logistics. The amount of logistics is the number of materials transferred between two logistics points in a certain period of time, also known as logistics strength. In the actual system, the geometric shape and materialized state of the material vary a lot. Therefore, this thesis finds a standard, by which all the material in the system will be converted to a unified quantity for the logistics system analysis and comparison. This is the equivalent amount of logistics. The formula is

$$
F=K \cdot G,
$$

where $F$ is the equivalent amount of logistics, $G$ is the weight of the material, and $K$ is the adjustment factor that is determined by other factors that influence the equivalent amount of logistics.

W. Sun thinks that the factors that determine the value of $K$ could include volume, density, shape, status, risk, and value, and he assigns, respectively, $-2,-1,1,2,3$, and 4 to handling easily, handling more easily, common, handling difficultly, handling more difficultly, and handling most difficultly. The final evaluation results are calculated by fuzzy comprehensive evaluation method, that is, $K$ value.

(b) Distance. Handling distance refers to the distance in which materials are transported from one facility to another during loading and unloading.

(c) Handling Costs. Handling costs refer to the costs paid by the material from one facility to another during loading and unloading. 
TABLE 1: Comprehensive Evaluation Index System of the Workplace layout.

\begin{tabular}{|c|c|c|}
\hline Object & First-level index & Second-level index \\
\hline \multirow{12}{*}{$\begin{array}{l}\text { Comprehensive evaluation of dynamic } \\
\text { facility layout problem of manufacturing } \\
\text { unit considering human factors } G\end{array}$} & \multirow{4}{*}{ Logistics factors $A$} & The amount of logistics $A 1$ \\
\hline & & Distance $A 2$ \\
\hline & & Handling costs $A 3$ \\
\hline & & Operator's posture $B 1$ \\
\hline & \multirow{4}{*}{ Human factors $B$} & Force strength $B 2$ \\
\hline & & Job difficulty $B 3$ \\
\hline & & Psychological load B4 \\
\hline & & Space comfort $B 5$ \\
\hline & \multirow{4}{*}{ Management factors $C$} & Product priority $C 1$ \\
\hline & & Reconfigurability $C 2$ \\
\hline & & Layout safety $C 3$ \\
\hline & & Line balance $C 4$ \\
\hline
\end{tabular}

TABLE 2: Force intensity grade division.

Operating load pressure performance

Evaluation value

Not feeling comfortable or breathing evenly, without heating or feeling tired 1

Slight discomfort, breathing accelerated, slight fever, feeling a little tired

Some discomfort, some asthma, some fever, feeling a little tired

Discomfort, asthma, fever, feeling tired

Very discomfort, asthma, overheating, very tired

\subsubsection{Human Factors}

(a) Operator's Posture. In the field of ergonomics, operator's posture is an important factor affecting people's fatigue and comfort. In this paper, human body model is established by using fiftieth percentile human body data. Using CATIA software for simulation evaluation, assuming that posture evaluates the $n$ parts of the human body, each score is $Q_{i}$ and the total score is $Q=(1 / n) \sum_{i=1}^{n} Q_{i}$. The total operator's posture is calculated according to the 5-point system [35].

(b) Force Strength. The force strength reflects the physiological load and the tension load caused by the weight of the material being handled. In this paper, the estimation of the force strength is determined according to the grade evaluation of operator's subjective perception pressure values of psychophysics. According to the performance characteristics of the operator, the grade evaluation value $(1,2,3,4,5)$ is given as the force strength score (see Table 2).

(c) Job Difficulty. Job difficulty refers to the operator's sense of work according to their level of difficulty; its value can be measured according to the time spent, error rate, and subjective comfort. In this paper, 5, 4, 3, 2, and 1 are used to assign five levels: "very difficult," "difficult," "moderately difficult," "slightly difficult," and "easy."

(d) Psychological Load. The operator bears not only the pressure of physical load, but also the impact of psychological load in the process of handling. The psychological load refers to the amount of psychological burden that the person has suffered in unit time. In this paper, according to the basic characteristics of the psychological load changes of the operator, the SWAT scale is used to divide the psychological load into three entries: time load, psychological effort load, and psychological stress load, each of which is divided into light, medium, and heavy. There are 27 kinds of condition, which correspond to 27 kinds of psychological load separately. The specific group and its score are shown in Table 3 [36]. The total psychological load of the operator is calculated according to the 5-point system.

(e) Space Comfort. In general, the human psychological space is greater than the operating space requirements. When the human psychological space requirements are limited, people will have a negative reaction. For the measurement of the crowdedness of urban buildings, Japan's Ashihara Yoshinobu et al. proposed a $D / H$ method that represents the relationship between road width $(D)$ and building height $(H)$ in a crossed form. For example, when the $D / H$ value is less than 1 , people will feel very depressed; when the $D / H$ value is equal to 1 , people will feel more symmetrical, and when $D / H$ is not less than 2, it will make people feel very open.

\subsubsection{Management Factors}

(a) Product Priority. Product priority refers to the parameters of the priority level of production when the enterprise received multiple orders at the same time. According to the preference of each customer $C_{k}$ for the competitor's products, the product priority is calculated based on the customer's perspective $\mathrm{PR}^{\mathrm{fu}}$. 
TABLE 3: Grouping and score of SWAT scale assessment of mental workload.

\begin{tabular}{|c|c|c|c|}
\hline Score & & TES & \\
\hline (1) & 1 & 1 & 1 \\
\hline (2) & 1 & 1 & 2 \\
\hline (3) & 1 & 1 & 3 \\
\hline (4) & 1 & 2 & 1 \\
\hline (5) & 1 & 2 & 2 \\
\hline (6) & 1 & 2 & 3 \\
\hline (7) & 1 & 3 & 1 \\
\hline (8) & 1 & 3 & 2 \\
\hline (9) & 1 & 3 & 3 \\
\hline (10) & 2 & 1 & 1 \\
\hline (11) & 2 & 1 & 2 \\
\hline (12) & 2 & 1 & 3 \\
\hline (13) & 2 & 2 & 1 \\
\hline (14) & 2 & 2 & 2 \\
\hline (15) & 2 & 2 & 3 \\
\hline (16) & 2 & 3 & 1 \\
\hline (17) & 2 & 3 & 2 \\
\hline (18) & 2 & 3 & 3 \\
\hline (19) & 3 & 1 & 1 \\
\hline (20) & 3 & 1 & 2 \\
\hline (21) & 3 & 1 & 3 \\
\hline (22) & 3 & 2 & 1 \\
\hline (23) & 3 & 2 & 2 \\
\hline (24) & 3 & 2 & 3 \\
\hline (25) & 3 & 3 & 1 \\
\hline (26) & 3 & 3 & 2 \\
\hline (27) & 3 & 3 & 3 \\
\hline
\end{tabular}

Note. $T, E$, and $S$ denote the time load, the psychological effort load, and the psychological stress load, respectively; 1, 2, and 3 denote the light, medium and heavy three degrees, respectively.

In order to achieve the interests of shareholders, this thesis uses financial performance indicators such as net profit, return on investment, and economic value added to calculate product priority based on financial perspective $\mathrm{PR}^{f}$. Similarly, use innovation, production, and after-sales service to calculate product priority based on the internal business perspective $\mathrm{PR}^{m}$; use resources for people, information systems, and enterprise processes to calculate product priority based on learning and growth perspective $\mathrm{PR}^{o}$.

Finally, the product priority is defined as follows:

$$
\mathrm{IPR}=w_{\mathrm{fu}} \mathrm{PR}^{\mathrm{fu}}+w_{f} \mathrm{PR}^{f}+w_{m} \mathrm{PR}^{m}+w_{o} \mathrm{PR}^{o}
$$

where $w_{\mathrm{fu}}, w_{f}, w_{m}$, and $w_{o}$ are weights of $\mathrm{PR}^{\mathrm{fu}}, \mathrm{PR}^{f}, \mathrm{PR}^{m}$, and $\mathrm{PR}^{o}$ [37].

(b) Reconfigurability. With the transformation of the product order and the processing technology, the facility variety and layout of the workshop also need to be replaced; this paper uses the reconfiguration to express this conversion ability.

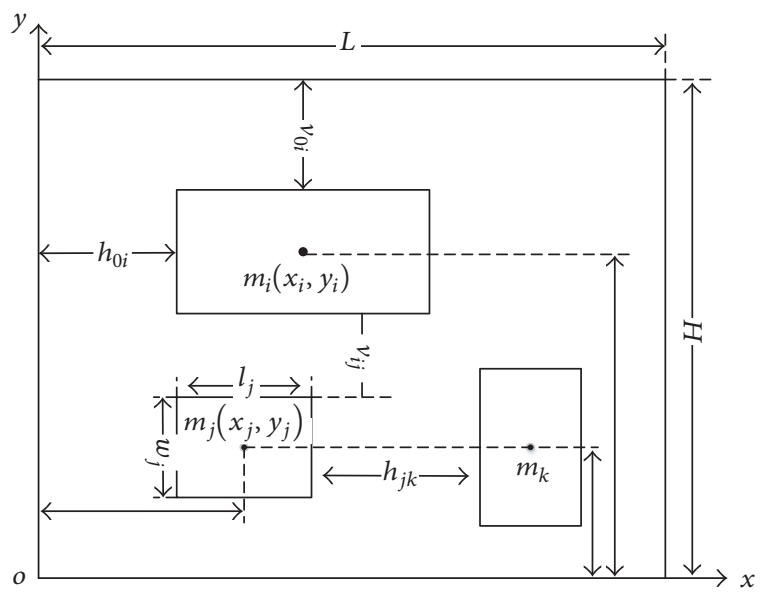

FIGURE 1: Optimization model of dynamic facility layout of manufacturing unit.

(c) Layout Safety. The layout is about positioning facilities in the factory. The safety problem is also important. About the safety, this paper mainly considers the safety distance between facilities (especially the high structure), the positioning of dangerous facilities, and the intricacy of water supply, gas supply, and sewage pipes, and so on.

(d) Line Balance. Line balance is about the facility layout. Line balance is the load analysis of all the processes of the production line. By adjusting the load distribution between the processes, the enterprise may eliminate all kinds of waste of waiting and improve the overall efficiency of the production line finally.

\section{Modeling of Design of Dynamic Facility Layout Considering Human Factors}

4.1. Problem Description. In a manufacturing unit there are $n$ facilities, in which the manufacturing unit uses multiline linear layout; this paper does not consider the addition or removal of manufacturing unit equipment. Assume the facilities are rectangular block envelope structure (other structures need to be transformed into rectangular block envelopes); their locations are represented by the coordinates of their center point; length and width are known; the minimum lateral distance ( $x$-axis) and longitudinal distance ( $y$-axis) between facility $i$ and facility $j$ are known. The establishment of reference lines and coordinate systems is shown in Figure 1.

4.2. The Construction and Related Parameters of Mathematical Model. Based on the evaluation index of manufacturing unit layout, this paper quantifies the risk of physical and mental damage to workers, determines the objective function of facility layout optimization combining logistics cost, unit reconfiguration cost, and area utilization, uses the basic ideas, principles, and methods of logistics optimization and human factor optimization, references the results of evaluation and analysis of the preceding layout scheme, and finally finds out the comprehensive optimal scheme satisfying all the evaluation indexes. The model this paper proposes is shown in Figure 2 [38]. 
TABLE 4: Symbolic definitions of dynamic facility layout problems.

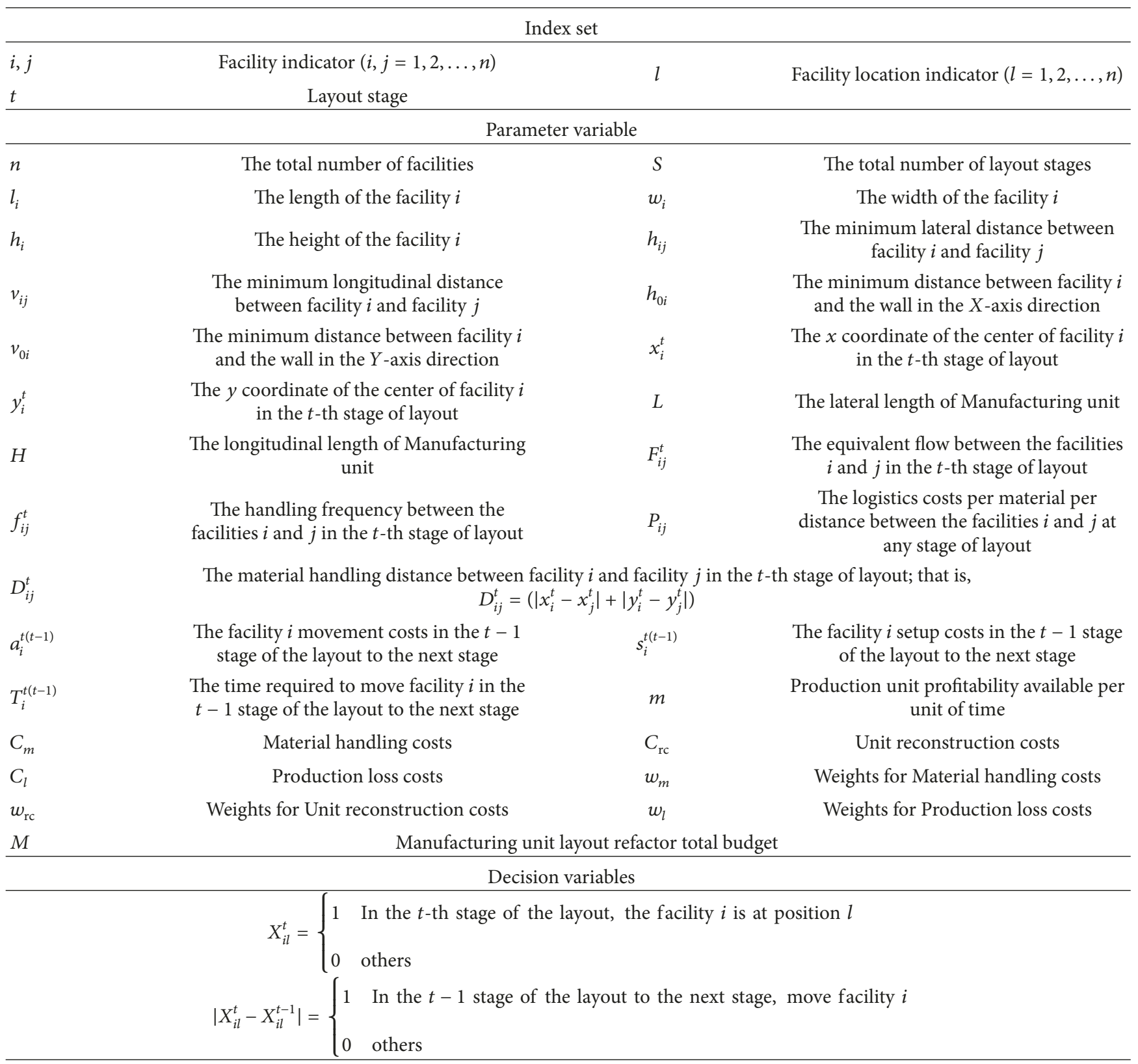

The symbols are defined as shown in Table 4 for convenience of description.

\subsection{Create an Objective Function}

4.3.1. Minimize the Risk of Physical and Mental Damage to Workers, Reflecting the Sustainability and Safety. In this paper, the risk of physical and mental damage to workers in the $t$-th stage is represented by human factors evaluation index $E_{i j}^{t}$. Workers physical and mental damage risk can be expressed as

$$
F_{1}=\sum_{t=1}^{S} \sum_{i=1}^{n} \sum_{j=1}^{n} f_{i j}^{t} D_{i j}^{t} E_{i j}^{t},
$$

where $E_{i j}^{t}=\sum_{k=1}^{4} w_{k} e_{(i j) k}^{t}, e_{(i j) k}^{t}(k=1,2,3,4)$, represent evaluation value of the operator's posture, force strength, job difficulty, and psychological load; $w_{k}(k=1,2,3,4)$ represent their weight for the human factors evaluation index. The explanation of $E_{i j}$ value is given in Table 5 .

4.3.2. Maximize the Area Utilization, Reflecting the High Efficiency. The area utilization of the manufacturing unit is the ratio of the sum of the area of the layout equipment and the total area of the rectangle enclosed by the layout scheme. Since the former is a fixed value, this paper uses minimize the envelope area to indicate the maximum area utilization. The layout envelope area can be expressed as 


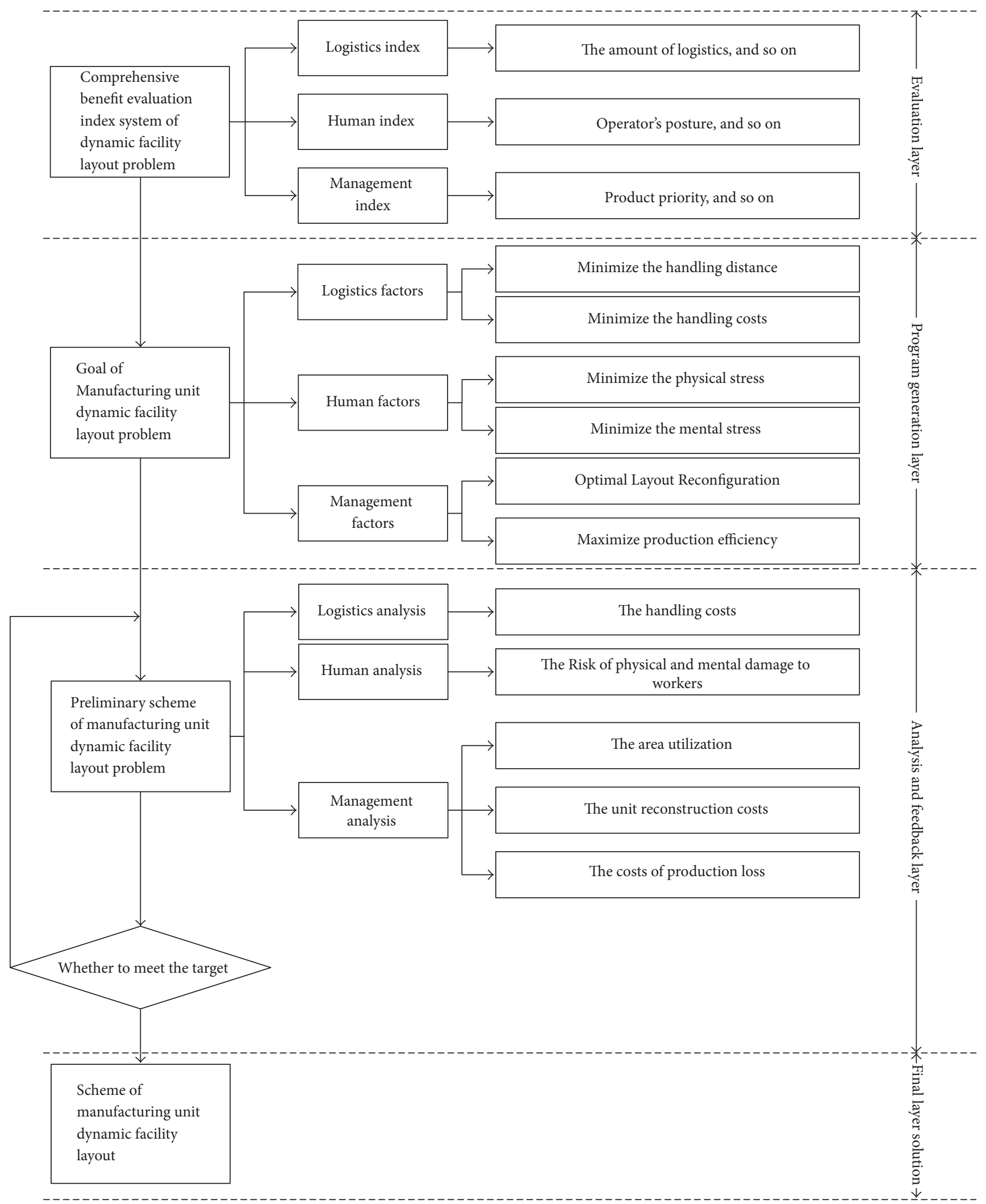

FIGURE 2: A framework model of dynamic facility layout design considering human factors. 
TABle 5: Explanation of $E_{i j}$ value.

\begin{tabular}{lcc}
\hline$E_{i j}$ value & Explanation & Impact on organization \\
\hline$[0,1]$ & Little risk of physical and mental damage to workers & Employees work normally \\
$(1,2]$ & Less risk of physical and mental damage to workers & Influence operation efficiency \\
$(2,3]$ & Normal risk of physical and mental damage to workers & Employees are asking for more sick leave \\
$(3,4]$ & Bigger risk of physical and mental damage to workers & Increase employee turnover costs \\
$(4,5]$ & Big risk of physical and mental damage to workers & Increase the cost of compensation \\
\hline
\end{tabular}

$$
F_{2}=\sum_{t=1}^{S}\left\{\max \left[\left|\left(x_{i}^{t}+\frac{1}{2} l_{i}\right)-\left(x_{j}^{t}-\frac{1}{2} l_{j}\right)\right| \times\left|\left(y_{i}^{t}+\frac{1}{2} w_{i}\right)-\left(y_{j}^{t}-\frac{1}{2} w_{j}\right)\right|\right]\right\} .
$$

4.3.3. Minimize Logistics and Relayout Costs, Reflecting the Economy and Flexibility. This paper considers the cost issues involved in the problem of the dynamic facility layout of the manufacturing unit. The total cost can be expressed as

$$
F_{3}=w_{m} C_{m}+w_{\mathrm{rc}} C_{\mathrm{rc}}+w_{l} C_{l}
$$

(1) Material Handling Costs. Material handling costs are the costs incurred in changing the material storage state and space position activity within the manufacturing unit.

$$
C_{m}=\sum_{t=1}^{S} \sum_{i=1}^{n} \sum_{j=1}^{n} F_{i j}^{t} f_{i j}^{t} D_{i j}^{t} P_{i j}
$$

(2) Unit Reconstruction Costs. Unit refactoring costs refer to the facility movement costs and facility setup costs for the reorganization of the original layout.

$$
C_{\mathrm{rc}}=\sum_{t=2}^{S} \sum_{i=1}^{n} \sum_{l=1}^{n}\left(a_{i}^{t(t-1)}+s_{i}^{t(t-1)}\right)\left|X_{i l}^{t}-X_{i l}^{t-1}\right| .
$$

(3) Production Loss Costs. Production loss costs are the loss of production caused by the closure of all the facilities of the manufacturing unit. This paper is expressed in terms of production profits that can be generated within the time of loss.

$$
C_{l}=\sum_{t=2}^{S} \sum_{i=1}^{n} \sum_{l=1}^{n} m T_{i}^{t(t-1)}\left|X_{i l}^{t}-X_{i l}^{t-1}\right|
$$

\subsection{Construct the Constraints of the Model}

4.4.1. Location Constraints. The location constraints require that each facility in a layout phase should be placed in only one location, and only one facility is allowed in one loca tion.

$$
\begin{aligned}
& \sum_{i=1}^{n} X_{i l}^{t}=1 \quad l=1,2, \ldots, n \\
& \sum_{l=1}^{n} X_{i l}^{t}=1 \quad i=1,2, \ldots, n .
\end{aligned}
$$

4.4.2. Spacing Constraints. The spacing constraints ensure that the two facilities do not overlap and that the longitudinal spacing of the manufacturing unit complies with the human space comfort requirements and safety requirements.

$$
\begin{aligned}
& \left|x_{i}^{t}-x_{j}^{t}\right| \geq \frac{\left(l_{i}+l_{j}\right)}{2}+h_{i j}, \quad y_{i}^{t}=y_{j}^{t} \\
& \left|y_{i}^{t}-y_{j}^{t}\right| \geq \frac{\left(w_{i}+w_{j}\right)}{2}+v_{i j}, \quad y_{i}^{t} \neq y_{j}^{t} \\
& \left|y_{i}^{t}-y_{j}^{t}\right| \leq \frac{\left(w_{i}+w_{j}\right)}{2}+\left(h_{i}+h_{j}\right) \times 2, \quad y_{i}^{t} \neq y_{j}^{t} .
\end{aligned}
$$

4.4.3. Boundary Constraints. The boundary constraints require that the unit layout does not exceed the boundaries of the shop floor and that the facility and the area boundary should be kept at a distance to facilitate staff walking or material handling.

$$
\begin{gathered}
\frac{l_{i}}{2}+h_{0 i} \leq x_{i}^{t} \leq L-\frac{l_{i}}{2}-h_{0 i} \\
\quad i=1,2, \ldots, n ; t=1,2, \ldots, S \\
\frac{w_{i}}{2}+v_{0 i} \leq y_{i}^{t} \leq H-\frac{w_{i}}{2}-v_{0 i} \\
\quad i=1,2, \ldots, n ; t=1,2, \ldots, S .
\end{gathered}
$$

4.4.4. Fixed Constraints. The fixed constraints require a facility to be fixed at a specific location in the facility layout, denoted by $D_{i}$, which does not consider the layout of other facilities.

$$
\begin{aligned}
D_{i} & =\left\{\frac{(x, y)}{x_{i}^{t}}-\frac{1}{2} l_{i} \leq x \leq x_{i}^{t}+\frac{1}{2} l_{i}, y_{i}^{t}-\frac{1}{2} w_{i} \leq y \leq y_{i}^{t}\right. \\
& \left.+\frac{1}{2} w_{i}\right\} .
\end{aligned}
$$

4.4.5. Security Constraints. The safety constraints ensure that dangerous facilities are concentrated in one particular area and that concentration dangers are closely monitored by 
TABLE 6: Parameters of each device. Unit: $\mathrm{m}$.

\begin{tabular}{lcccc}
\hline Facility number & 1 & 2 & 3 & 4 \\
Facility size $\left(l_{i} \times w_{i} \times h_{i}\right)$ & $2.2 \times 2.4 \times 2.5$ & $3.0 \times 2.5 \times 2.0$ & $2.5 \times 2.0 \times 2.2$ & 7 \\
\hline Facility number & 5 & 6 & $2.2 \times 2.5 \times 2.8$ & $3.0 \times 2.2 \times 2.0$ \\
Facility size $\left(l_{i} \times w_{i} \times h_{i}\right)$ & $2.5 \times 2.0 \times 2.2$ & $4.0 \times 2.7 \times 3.0$ & 11 & $3.0 \times 1.5 \times 2.5$ \\
\hline Facility number & 9 & 10 & $3.0 \times 2.2 \times 2.8$ & 12 \\
Facility size $\left(l_{i} \times w_{i} \times h_{i}\right)$ & $3.5 \times 2.7 \times 3.5$ & $2.5 \times 2.0 \times 2.4$ & $2.5 \times 3.0 \times 3.2$ \\
\hline
\end{tabular}

TABLE 7: The production process path of the product.

\begin{tabular}{lccccc}
\hline Product & Components & Demand & $\begin{array}{c}\text { Handling } \\
\text { quantity per } \\
\text { time }\end{array}$ & Adjustment factor $K$ & Facility routing \\
\hline \multirow{2}{*}{$A$} & $A 1$ & 200 & 20 & 1.1380 & $1-10-7-8-5-12$ \\
& $A 2$ & 100 & 10 & 0.2970 & $1-2-11-5-3-12$ \\
$B$ & $B 1$ & 160 & 10 & 0.8820 & $5-9-8-3-1-10$ \\
& $B 2$ & 320 & 16 & 0.6850 & $1-4-3-10-6-12$ \\
$C$ & $C 1$ & 120 & 8 & 0.8180 & $2-7-6-11-4-9-12$ \\
& $C 2$ & 480 & 30 & 1.0730 & $8-3-11$ \\
\hline
\end{tabular}

workers and managers to effectively prevent from accidents. Similar to fixed constraints, the difference is that dangerous facilities can be changed in a specific area, and specific areas can be selected with the nature and layout requirements of the dangerous facility.

4.4.6. Budget Constraints. The budget constraints ensure that the total refactoring costs are within budget.

$$
\begin{aligned}
& \sum_{t=2}^{S} \sum_{l=1}^{n} \sum_{i=1}^{n}\left(a_{i}^{t(t-1)}+s_{i}^{t(t-1)}+m T_{i}^{t(t-1)}\right)\left|X_{i l}^{t}-X_{i l}^{t-1}\right| \\
& \quad \leq M
\end{aligned}
$$

where $M>0$.

\subsection{The Steps of Dynamic Layout Problem Unit Considering} Human Factors. (1) Determine product priority and layout phase.

(2) Depending on the line balance, the amount of production equipment is determined by the time taken by the manufacturing process station where the product is produced at the first layout stage.

(3) Combine the area factor to determine the number of production equipment.

(4) The optimal layout scheme is obtained by using the improved $\mathrm{ABC}$ algorithm.

4.6. An Improved ABC Algorithm for Solving the Layout of Manufacturing Unit. The essence of the manufacturing dynamic facility layout problem is the optimal design of the two-dimensional coordinates of the facility. Assuming that the manufacturing unit has $n$ facilities, then the $t$-th layout phase solution $Z_{i}^{t}(i=1,2, \ldots, \mathrm{SN} ; t=1,2, \ldots, S)$ is a $2 n$ dimension vector, the former $n$ dimension represents the $X$ coordinate of each facility in the $t$-th layout stage facility layout, and the rear $n$ dimension represents the $Y$ coordinate.

$$
\begin{aligned}
Z_{i}^{t} & =\left(z_{i \cdot 1}^{t}, z_{i \cdot 2}^{t}, \ldots, z_{i \cdot 2 n}^{t}\right)=\left(x_{i 1}^{t}, \ldots, x_{i n}^{t}, y_{i 1}^{t}, \ldots, y_{i n}^{t}\right) \\
Z_{i} & =\left(Z_{i}^{1}, Z_{i}^{2}, \ldots, Z_{i}^{S}\right) \\
Z & =\left(Z_{1}, Z_{2}, \ldots, Z_{\mathrm{SN}}\right) .
\end{aligned}
$$

Construct the fitness function of the algorithm:

$$
\text { fit }_{i}=\left[1+\left|f\left(z_{i}\right)\right|\right]^{-\operatorname{sgn}\left[f\left(z_{i}\right)\right]},
$$

where $f\left(z_{i}\right)=F+\lg [\max (\varepsilon, P)] \varepsilon \rightarrow 0, F$ is the objective function, and $F=\alpha_{1} \cdot \lg F_{1}+\alpha_{2} \cdot \lg F_{2}+\alpha_{3} \cdot \lg F_{3}, \alpha_{1}, \alpha_{2}, \alpha_{3}$ are the weights of the above three optimization goals (for different problems, ask experts to choose different weights), $P$ is the penalty function, and $P=(1 / 2) N\left(\sum_{k=1}^{2}\left[\left|h_{k}(i)\right|+\right.\right.$ $\left.\left.h_{k}(i)\right]+\sum_{k=1}^{8}\left[\left|g_{k}(i)\right|+g_{k}(i)\right]\right), N$ for the penalty factor. While playing the effect of punishment at the same time, to avoid the election probability tending to 0 because $f\left(z_{i}\right)$ is too large, this paper proposes an adaptive penalty factor $N=$ $a^{F \cdot \lg [\max (\varepsilon, P)]} 0<a<1$. In this paper $h_{k}(i)$ (using $h(x)-c=0$ said) denotes the fixed constraint; $g_{k}(i)$ (Using $g(x)-c \leq 0$ said) in this paper represent the spacing constraints, boundary constraints, security constraints, and budget constraints.

\section{Case Study}

Case workshop is a CNC machine manufacturing unit, the unit area for the rectangular site is $25 \times 18 \mathrm{~m}^{2}$, there are 12 machines, this stage received the orders of three products including $A, B$, and $C$, calculate $A, B$, and $C$, three products priority, and get $\mathrm{IPR}_{A}>\mathrm{IPR}_{B}>\mathrm{IPR}_{C}$. The size of each machine and the process path of the product are shown in Tables 6 and 7, respectively. The minimum safe spacing in 

component were

$$
\begin{aligned}
& {\left[P_{i j}\right]=\left[\begin{array}{cccccccccccc}
0 & 3 & 5 & 2 & 7 & 5 & 9 & 6 & 3 & 6 & 8 & 1 \\
3 & 0 & 3 & 4 & 6 & 2 & 7 & 8 & 4 & 9 & 3 & 5 \\
5 & 3 & 0 & 6 & 1 & 7 & 4 & 8 & 9 & 3 & 6 & 2 \\
2 & 4 & 6 & 0 & 5 & 1 & 6 & 8 & 9 & 3 & 2 & 9 \\
7 & 6 & 1 & 5 & 0 & 7 & 4 & 8 & 8 & 3 & 6 & 5 \\
5 & 2 & 7 & 1 & 7 & 0 & 1 & 4 & 1 & 8 & 2 & 2 \\
9 & 7 & 4 & 6 & 4 & 1 & 0 & 7 & 5 & 3 & 2 & 6
\end{array}\right]=\left[E_{i j}^{C}\right]=\left[\begin{array}{llllllllllll}
0 & 0 & 0 & 0 & 0 & 0 & 0 & 0 & 0 & 0 & 3 & 0 \\
0 & 0 & 0 & 0 & 0 & 1 & 0 & 0 & 0 & 0 & 0 & 0 \\
0 & 0 & 4 & 0 & 0 & 0 & 0 & 0 & 0 & 0 & 0 & 0 \\
0 & 0 & 0 & 0 & 0 & 0 & 0 & 0 & 0 & 0 & 0 & 3 \\
0 & 0 & 0 & 0 & 0 & 0 & 0 & 0 & 0 & 0 & 0 & 0 \\
0 & 0 & 0 & 4 & 0 & 0 & 0 & 0 & 0 & 0 & 0 & 0 \\
0 & 0 & 0 & 0 & 0 & 0 & 0 & 0 & 0 & 0 & 0 & 0
\end{array}\right] .} \\
& {\left[E_{i j}^{C}\right]=\left[\begin{array}{llllllllllll}
0 & 0 & 0 & 0 & 0 & 0 & 0 & 0 & 0 & 0 & 0 & 0 \\
0 & 0 & 0 & 0 & 0 & 0 & 4 & 0 & 0 & 0 & 0 & 0 \\
0 & 0 & 0 & 0 & 0 & 0 & 0 & 0 & 0 & 0 & 5 & 0 \\
0 & 0 & 0 & 0 & 0 & 0 & 0 & 0 & 2 & 0 & 0 & 0 \\
0 & 0 & 0 & 0 & 0 & 0 & 0 & 0 & 0 & 0 & 0 & 0 \\
0 & 0 & 0 & 0 & 0 & 0 & 0 & 0 & 0 & 0 & 3 & 0 \\
0 & 0 & 0 & 0 & 0 & 1 & 0 & 0 & 0 & 0 & 0 & 0 \\
0 & 0 & 4 & 0 & 0 & 0 & 0 & 0 & 0 & 0 & 0 & 0 \\
0 & 0 & 0 & 0 & 0 & 0 & 0 & 0 & 0 & 0 & 0 & 3 \\
0 & 0 & 0 & 0 & 0 & 0 & 0 & 0 & 0 & 0 & 0 & 0 \\
0 & 0 & 0 & 4 & 0 & 0 & 0 & 0 & 0 & 0 & 0 & 0 \\
0 & 0 & 0 & 0 & 0 & 0 & 0 & 0 & 0 & 0 & 0 & 0
\end{array}\right] .}
\end{aligned}
$$$$
\begin{array}{llllllllllll}
6 & 8 & 8 & 8 & 8 & 4 & 7 & 0 & 3 & 7 & 4 & 5
\end{array}
$$$$
\begin{array}{llllllllllll}
3 & 4 & 9 & 9 & 8 & 1 & 5 & 3 & 0 & 2 & 6 & 1
\end{array}
$$$$
\begin{array}{llllllllllll}
6 & 9 & 3 & 3 & 3 & 8 & 3 & 7 & 2 & 0 & 3 & 9
\end{array}
$$$$
\begin{array}{llllllllllll}
8 & 3 & 6 & 2 & 6 & 2 & 2 & 4 & 6 & 3 & 0 & 4
\end{array}
$$$$
\left.\begin{array}{llllllllllll}
1 & 5 & 2 & 9 & 5 & 2 & 6 & 5 & 1 & 9 & 4 & 0
\end{array}\right]
$$$$
\left[E_{i j}^{A}\right]=\left[\begin{array}{llllllllllll}
0 & 1 & 0 & 0 & 0 & 0 & 0 & 0 & 0 & 4 & 0 & 0 \\
0 & 0 & 0 & 0 & 0 & 0 & 0 & 0 & 0 & 0 & 2 & 0 \\
0 & 0 & 0 & 0 & 0 & 0 & 0 & 0 & 0 & 0 & 0 & 1 \\
0 & 0 & 0 & 0 & 0 & 0 & 0 & 0 & 0 & 0 & 0 & 0 \\
0 & 0 & 2 & 0 & 0 & 0 & 0 & 0 & 0 & 0 & 0 & 5 \\
0 & 0 & 0 & 0 & 0 & 0 & 0 & 0 & 0 & 0 & 0 & 0 \\
0 & 0 & 0 & 0 & 0 & 0 & 0 & 3 & 0 & 0 & 0 & 0 \\
0 & 0 & 0 & 0 & 4 & 0 & 0 & 0 & 0 & 0 & 0 & 0 \\
0 & 0 & 0 & 0 & 0 & 0 & 0 & 0 & 0 & 0 & 0 & 0 \\
0 & 0 & 0 & 0 & 0 & 0 & 5 & 0 & 0 & 0 & 0 & 0 \\
0 & 0 & 0 & 0 & 4 & 0 & 0 & 0 & 0 & 0 & 0 & 0 \\
0 & 0 & 0 & 0 & 0 & 0 & 0 & 0 & 0 & 0 & 0 & 0
\end{array}\right]
$$$$
\left[E_{i j}^{B}\right]=\left[\begin{array}{llllllllllll}
0 & 0 & 0 & 3 & 0 & 0 & 0 & 0 & 0 & 4 & 0 & 0 \\
0 & 0 & 0 & 0 & 0 & 0 & 0 & 0 & 0 & 0 & 0 & 0 \\
2 & 0 & 0 & 0 & 0 & 0 & 0 & 0 & 0 & 2 & 0 & 0 \\
0 & 0 & 3 & 0 & 0 & 0 & 0 & 0 & 0 & 0 & 0 & 0 \\
0 & 0 & 0 & 0 & 0 & 0 & 0 & 0 & 3 & 0 & 0 & 0 \\
0 & 0 & 0 & 0 & 0 & 0 & 0 & 0 & 0 & 0 & 0 & 4 \\
0 & 0 & 0 & 0 & 0 & 0 & 0 & 0 & 0 & 0 & 0 & 0 \\
0 & 0 & 3 & 0 & 0 & 0 & 0 & 0 & 0 & 0 & 0 & 0 \\
0 & 0 & 0 & 0 & 0 & 0 & 0 & 2 & 0 & 0 & 0 & 0 \\
0 & 0 & 0 & 0 & 0 & 4 & 0 & 0 & 0 & 0 & 0 & 0 \\
0 & 0 & 0 & 0 & 0 & 0 & 0 & 0 & 0 & 0 & 0 & 0 \\
0 & 0 & 0 & 0 & 0 & 0 & 0 & 0 & 0 & 0 & 0 & 0
\end{array}\right]
$$

From the initial data, it can be seen that the cost $P_{i j}$ and human factor evaluation index $E_{i j}$ of the same facilities are not increasing simultaneously. That is to say, the structure of the facilities, the way workers operate, the amount of resources, and the operating environment do not affect the unit cost of facilities, and the cost of facilities is low while the human factor evaluation index is very high due to the limitation of the quantity of resources. Meanwhile, due to the different production processes and equipment routes of products, there is a big difference between the logistics intensity and the comprehensive evaluation index of human factors of different products but same two facilities; the layout should be changed in order to satisfy the process flow facility route of the next product when the product is replaced. The case applies optimization model proposed in this paper (according to the enterprise vision and expert experience, $\alpha_{1}=0.5, \alpha_{2}=0.1$, and $\alpha_{3}=0.4$ ) and divides it into three stages on the basis of $A, B$, and $C$ three products and finally obtains the dynamic facility coordinates at all stages. The results are compared with the static facility coordinate only considering the material handling cost, as shown in Table 8 (note that $S$ is the static one and $D$ is the dynamic multiobject one).

The two facility layouts were evaluated, respectively, and the results are shown in Table 9. From the results, it can be concluded that although the total costs of the model in this paper increased by $9 \%$, because the model takes into account the refactoring factors in the layout of unit facilities, the layout adjusts better to the requirements of each product production. In the end, the material handling costs reduced by $4.5 \%$, the area utilization increased by $18.5 \%$, the risk of physical and mental damage of workers reduced by $28.5 \%$, and average $E_{i j}$ value drops from $(3,4]$ to $(2,3]$ in the multiobjective optimization model proposed in this paper, which can coordinate between efficiency and labor intensity, reduce the fatigue strength of workers, and improve the overall sustainability and safety of the facilities. At the same time, compared with the PSO and basic ABC algorithm, the improved $A B C$ algorithm proposed in this paper only needs fewer iterations, greatly improves in the optimization 
TABLE 8: The coordinates of the facilities of the two schemes.

\begin{tabular}{|c|c|c|c|c|c|c|c|c|c|c|}
\hline \multicolumn{2}{|c|}{ Facility number } & \multicolumn{3}{|c|}{1} & \multicolumn{3}{|c|}{2} & \multicolumn{3}{|c|}{3} \\
\hline \multirow{2}{*}{$S$} & $X$ & \multicolumn{3}{|c|}{16.9153} & \multicolumn{3}{|c|}{6.9951} & \multicolumn{3}{|c|}{16.8302} \\
\hline & $Y$ & \multicolumn{3}{|c|}{14.7000} & \multicolumn{3}{|c|}{14.3284} & \multicolumn{3}{|c|}{4.2415} \\
\hline \multirow{2}{*}{$D$} & $X$ & 9.16 & 9.08 & 9.56 & 5.63 & 14.09 & 13.16 & 20.61 & 13.10 & 2.75 \\
\hline & $Y$ & 6.19 & 7.80 & 7.81 & 6.49 & 4.11 & 4.57 & 6.89 & 14.90 & 4.28 \\
\hline \multicolumn{2}{|c|}{ Facility number } & \multicolumn{3}{|c|}{4} & \multicolumn{3}{|c|}{5} & \multicolumn{3}{|c|}{6} \\
\hline \multirow{2}{*}{$S$} & $X$ & \multicolumn{3}{|c|}{22.0000} & \multicolumn{3}{|c|}{14.7549} & \multicolumn{3}{|c|}{10.1677} \\
\hline & $Y$ & \multicolumn{3}{|c|}{3.6783} & \multicolumn{3}{|c|}{8.8735} & \multicolumn{3}{|c|}{8.9765} \\
\hline \multirow{2}{*}{$D$} & $X$ & 4.10 & 8.82 & 17.66 & 19.16 & 21.48 & 16.68 & 12.78 & 21.50 & 21.50 \\
\hline & $Y$ & 13.39 & 3.77 & 9.43 & 12.49 & 14.64 & 4.30 & 13.32 & 3.45 & 14.21 \\
\hline \multicolumn{2}{|c|}{ Facility number } & \multicolumn{3}{|c|}{7} & \multicolumn{3}{|c|}{8} & \multicolumn{3}{|c|}{9} \\
\hline \multirow{2}{*}{$S$} & $X$ & \multicolumn{3}{|c|}{12.9526} & \multicolumn{3}{|c|}{19.0917} & \multicolumn{3}{|c|}{4.7857} \\
\hline & $Y$ & \multicolumn{3}{|c|}{14.0815} & \multicolumn{3}{|c|}{8.8826} & & 8.8156 & \\
\hline$D$ & $X$ & 10.48 & 7.67 & 7.25 & 17.22 & 3.89 & 7.01 & 19.89 & 7.75 & 7.86 \\
\hline & $Y$ & 13.46 & 10.81 & 9.96 & 14.14 & 4.45 & 4.50 & 4.23 & 14.55 & 14.55 \\
\hline $\mathrm{Fac}$ & ber & & 10 & & & 11 & & & 12 & \\
\hline$S$ & $X$ & & 4.6178 & & & 21.7082 & & & 11.5245 & \\
\hline & $Y$ & & 3.1000 & & & 14.8000 & & & 3.6000 & \\
\hline$D$ & $X$ & 10.80 & 4.22 & 13.15 & 16.41 & 18.93 & 19.17 & 21.42 & 20.54 & 18.13 \\
\hline & $Y$ & 7.25 & 10.81 & 4.29 & 6.94 & 11.62 & 5.11 & 9.97 & 9.87 & 14.40 \\
\hline
\end{tabular}

TABLE 9: Comparison of the results of the two schemes.

\begin{tabular}{lcccc}
\hline Schemes & Objective function & $\begin{array}{c}\text { Damage risk of } \\
\text { workers }\end{array}$ & Average $E_{i j}$ value & Area utilization \\
\hline$S$ & 4.55 & $1.8513 * 10^{4}$ & 3.84 & $38.71 \%$ \\
$D$ & 4.48 & $1.3235 * 10^{4}$ & 2.99 & $45.87 \%$ \\
\hline Schemes & Total cost & Material handling & Unit & Production loss cost \\
\hline$S$ & $2.9359 * 10^{5}$ & cost & reconstruction cost & 0 \\
$D$ & $3.2121 * 10^{5}$ & $2.9359 * 10^{5}$ & 0 & $0.102 * 10^{5}$ \\
\hline
\end{tabular}

ability, and is much shorter in the running time and has obvious advantages in solving optimization problems.

\section{Conclusions}

With the introduction of industry 4.0, the humanization of production has become one of the most important directions of future factory change. That is, the factory in the future cannot be completely unmanned; it is to make people more efficient and scientific in the production activities of future intelligent engineering and make the production system more consistent with human factors; the factory of the future is certainly humane intelligent factory. But, meanwhile, the competition has become much more severe. And, now, clients require not only new products with high quality but also personalization and fast delivery. Therefore, it is of great significance for the future factory development to carry out the application research of human factors in the field of workshop production. Based on the basic idea of "humanoriented," this paper puts forward a methodology for systematically analyzing, designing, and evaluating the layout of manufacturing units, integrated logistics optimization, and optimization of human factors, so as to make the layout optimization design not only ensure the operation efficiency but decrease the risk of physical and mental damage to workers. Through the case study, the results show that the optimized layout proposed in this paper can improve the efficiency and flexibility and reduce the probability of accident caused by misoperation. All these will create advantages in market competition. The innovation of this paper includes mainly the following 3 aspects.

(1) Innovation of evaluation index system for facility layout of manufacturing units: based on layout optimization goal of "design for people," this paper overcomes the optimization goal only emphasizing one sidedness of the logistics efficiency or cost in the previous researches, integrates logistics factors and physiological and psychological factors of the operator and layout reconfiguration factor caused by industry 4.0, comprehensively evaluates the layout of manufacturing unit, and constructs the optimal objective of facility layout optimization, that is, minimizing the cost of logistics and the risk of physical and mental damage to workers.

(2) Modeling innovation for dynamic facility layout problem of manufacturing unit considering human factors: based 
on the evaluation index of layout optimization, this paper constructs the optimal target, puts forward new mathematical model for dynamic facility layout problem of manufacturing unit considering human factors, randomly generates preliminary scheme satisfying all constraints, and finally gets the optimal layout after iteration. Because the dimension of each objective function is different, this paper uses logarithmic normalization method to unify the dimensions. Meanwhile, the logistics objective and the human factors goal cannot achieve the best at the same time. The weight of each objective function should be determined according to the actual situation of enterprises and expert evaluation.

(3) Innovation of solving algorithm of improved ABC: in view of the shortcomings of low convergence precision and slow convergence rate of the basic $\mathrm{ABC}$ algorithm, this paper improves the search strategy and selection strategy of the basic ABC algorithm by using the evolutionism of PSO and significantly improves the computational efficiency of the algorithm. In the case study, the convergence speed of the improved $\mathrm{ABC}$ algorithm proposed in this paper is very fast in the 100 previous iterations, and the optimal solution of the model is not updated in the 300th generation.

\section{Conflicts of Interest}

The authors declare no conflicts of interest.

\section{Acknowledgments}

This work has been supported by "Ministry of Education, Humanities and Social Science Fund," no. 15YJC630058, and the Fundamental Research Funds for the Central Universities, no. 2017MS083.

\section{References}

[1] D. J. Fang, "Design of Intelligent Factory and Intelligent Logistics System for Industry 4.0," Logistics Technology and Application, vol. 6, pp. 90-94, 2015.

[2] F. Y. Meng, "Man-machine integration of "big data + industrial cloud" industrial 4.0 era," Electronic Technology and Software Engineering, vol. 20, pp. 201-203, 2016.

[3] Y. U. Rui-Feng, Y. X. Wang, and Y. Q. Zhu, “Optimizing research on facility layout problem in workplace based on human factors," Engineering-Theory \& Practice, 2004.

[4] L.-Y. Tao, Z.-F. Wang, Q. Nie, and M.-T. Liang, "Optimization design method of unit facilities layout considering human factors," Jisuanji Jicheng Zhizao Xitong/Computer Integrated Manufacturing Systems, CIMS, vol. 20, no. 12, pp. 2973-2979, 2014.

[5] J. Z. Huang, G. Y. Hu, and M. Li, "The Allocative Suitability of Community Facilities from the Perspective of the Elderly-Based on Walk Score Method," Urban Planning Forum, vol. 6, 2016.

[6] J. Xu and X. Song, "Multi-objective dynamic layout problem for temporary construction facilities with unequal-area departments under fuzzy random environment," Knowledge-Based Systems, vol. 81, pp. 30-45, 2015.

[7] R. Matai, "Solving multi objective facility layout problem by modified simulated annealing," Applied Mathematics and Computation, vol. 261, pp. 302-311, 2015.
[8] S. Ingole and D. Singh, "Unequal-area, fixed-shape facility layout problems using the firefly algorithm," Engineering Optimization, vol. 49, no. 7, pp. 1097-1115, 2017.

[9] G. Y.-H. Chen and J.-C. Lo, "Dynamic facility layout with multiobjectives," Asia-Pacific Journal of Operational Research, vol. 31, no. 4, article 1450027, 2014.

[10] Y. F. Qu, D. Jiang, G. Y. Gao, and Y. J. Huo, "Pipe routing approach for aircraft engines based on ant colony optimization," Journal of Aerospace Engineering, vol. 29, no. 3, article 04015057, 2015.

[11] Y. Zhang and X.-L. Bai, "Intelligent multi-pipes layout for aeroengine based on CAFSC algorithm," Journal of Northeastern University, vol. 37, no. 5, pp. 683-687, 2016.

[12] I. Jerin Leno, S. Saravana Sankar, and S. G. Ponnambalam, "An elitist strategy genetic algorithm using simulated annealing algorithm as local search for facility layout design," The International Journal of Advanced Manufacturing Technology, vol. 84, no. 5-8, pp. 787-799, 2016.

[13] M. M. Azevedo, J. A. Crispim, and J. Pinho de Sousa, "A dynamic multi-objective approach for the reconfigurable multi-facility layout problem," Journal of Manufacturing Systems, vol. 42, pp. 140-152, 2017.

[14] A. W. A. Hammad, A. Akbarnezhad, and D. Rey, "A multiobjective mixed integer nonlinear programming model for construction site layout planning to minimise noise pollution and transport costs," Automation in Construction, vol. 61, pp. 73-85, 2016.

[15] Z. Li, W. Shen, J. Xu, and B. Lev, "Bilevel and multi-objective dynamic construction site layout and security planning," Automation in Construction, vol. 57, pp. 1-16, 2015.

[16] H. Pourvaziri and H. Pierreval, "Dynamic facility layout problem based on open queuing network theory," European Journal of Operational Research, vol. 259, no. 2, pp. 538-553, 2017.

[17] I. N. Papadaki and A. P. Chassiakos, "Multi-objective Construction Site Layout Planning Using Genetic Algorithms," in Proceedings of the 5th Creative Construction Conference, CCC 2016, pp. 20-27, June 2016.

[18] A. Saraswat, U. Venkatadri, and I. Castillo, "A framework for multi-objective facility layout design," Computers \& Industrial Engineering, vol. 90, pp. 167-176, 2015.

[19] I. M. Hakim and T. Y. M. Zagloel, "An ergonomic evaluation and assessment to improve productivity for piston assembly line," Advanced Science Letters, vol. 22, no. 7, pp. 1791-1794, 2016.

[20] M. X. Jia and M. L. Wang, "A Preliminary Study on the Relationship between the Health of Human Spine and the Comfort of Office Chair," Science and Technology Innovation and Application, vol. 6, pp. 40-40, 2016.

[21] T. Karakolis, J. Barrett, and J. P. Callaghan, "A comparison of trunk biomechanics, musculoskeletal discomfort and productivity during simulated sit-stand office work," Ergonomics, vol. 59, no. 10, pp. 1-13, 2016.

[22] J. Santos, J. S. Baptista, P. R. R. Monteiro, A. S. Miguel, R. Santos, and M. A. P. Vaz, "The influence of task design on upper limb muscles fatigue during low-load repetitive work: A systematic review," International Journal of Industrial Ergonomics, vol. 52, pp. 78-91, 2016.

[23] D. Gorecky, M. Schmitt, M. Loskyll et al., "Human-machineinteraction in the industry 4.0 era," Management Science, vol. 23, no. 6, pp. 595-605, 2014.

[24] K. Z. Gao, P. N. Suganthan, Q. K. Pan, T. J. Chua, C. S. Chong, and T. X. Cai, "An improved artificial bee colony algorithm 
for flexible job-shop scheduling problem with fuzzy processing time," Expert Systems with Applications, vol. 65, pp. 52-67, 2016.

[25] F. Zhong, H. Li, and S. Zhong, "An improved artificial bee colony algorithm with modified-neighborhood-based update operator and independent-inheriting-search strategy for global optimization," Engineering Applications of Artificial Intelligence, vol. 58, pp. 134-156, 2017.

[26] L. Asadzadeh, "A parallel artificial bee colony algorithm for the job shop scheduling problem with a dynamic migration strategy," Computers \& Industrial Engineering, vol. 102, pp. 359367, 2016.

[27] R. Zhang, P.-C. Chang, S. Song, and C. Wu, "A multi-objective artificial bee colony algorithm for parallel batch-processing machine scheduling in fabric dyeing processes," KnowledgeBased Systems, vol. 116, pp. 114-129, 2017.

[28] D. H. Tran, M. Y. Cheng, and M. T. Cao, "Solving resourceconstrained project scheduling problems using hybrid artificial bee colony with differential evolution," Journal of Computing in Civil Engineering, vol. 30, no. 4, article 04015065, 2015.

[29] S. Babaeizadeh and R. Ahmad, "An efficient artificial bee colony algorithm for constrained optimization problems," Journal of Engineering and Applied Sciences, vol. 9, no. 10, pp. 405-413, 2014.

[30] T. Bindima and E. Elias, "A novel design and implementation technique for low complexity variable digital filters using multiobjective artificial bee colony optimization and a minimal spanning tree approach," Engineering Applications of Artificial Intelligence, vol. 59, pp. 133-147, 2017.

[31] J. Luo, Q. Liu, Y. Yang, X. Li, M. R. Chen, and W. Cao, "An artificial bee colony algorithm for multi-objective optimisation," Applied Soft Computing, vol. 50, pp. 235-251, 2017.

[32] A. Kishor, P. K. Singh, and J. Prakash, "NSABC: Non-dominated sorting based multi-objective artificial bee colony algorithm and its application in data clustering," Neurocomputing, vol. 216, pp. 514-533, 2016.

[33] B. Wang, Z. Guan, S. Ullah, X. Xu, and Z. He, "Simultaneous order scheduling and mixed-model sequencing in assemble-toorder production environment: a multi-objective hybrid artificial bee colony algorithm," Journal of Intelligent Manufacturing, vol. 28, no. 2, pp. 1-18, 2017.

[34] M. Saravanan and P. V. Arulkumar, "An artificial bee colony algorithm for design and optimize the fixed area layout problems," The International Journal of Advanced Manufacturing Technology, vol. 78, no. 9-12, pp. 2079-2095, 2015.

[35] F. Kong and Z. Ye, "Research on Evaluation Method Framework Model of Production Job Operability," Journal of Mechanical Engineering, 2017.

[36] L. Jin and L. I. Cheng, "Study on the mental workload of highplace operating personnel with the subjective assessment method of swat scale," Safety \& Environmental Engineering, 2015.

[37] Y. Li, X. Luo, Y. Han, and J. Yao, "Determination of integrated priority ratings of customer requirements in product planning based on balanced scorecard," China Mechanical Engineering, 2010.

[38] P. Li, Z. Fan, J. Zhou, and J. Deng, "Facility layout model of production line based on operation comfort," Applied Mechanics and Materials, vol. 214, pp. 500-504, 2012. 


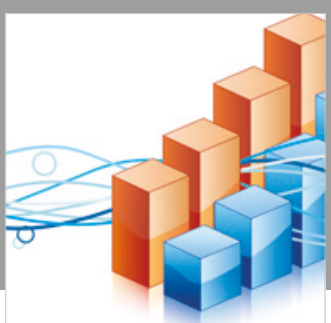

Advances in

Operations Research

\section{-n-m}
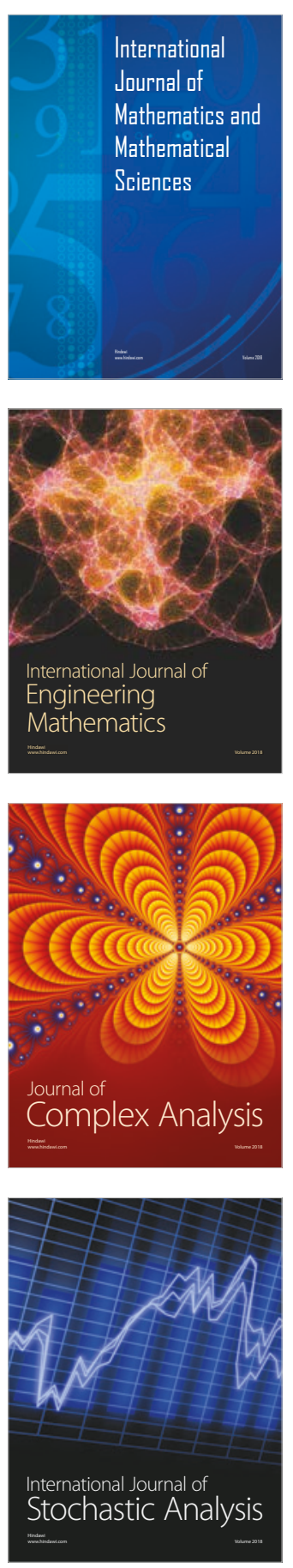
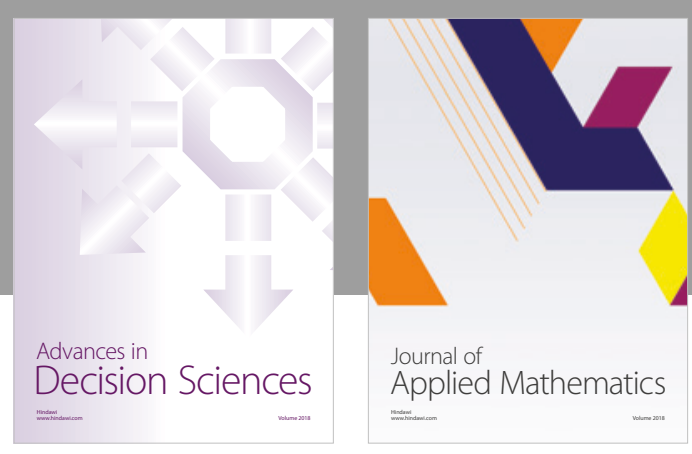

Journal of

Applied Mathematics
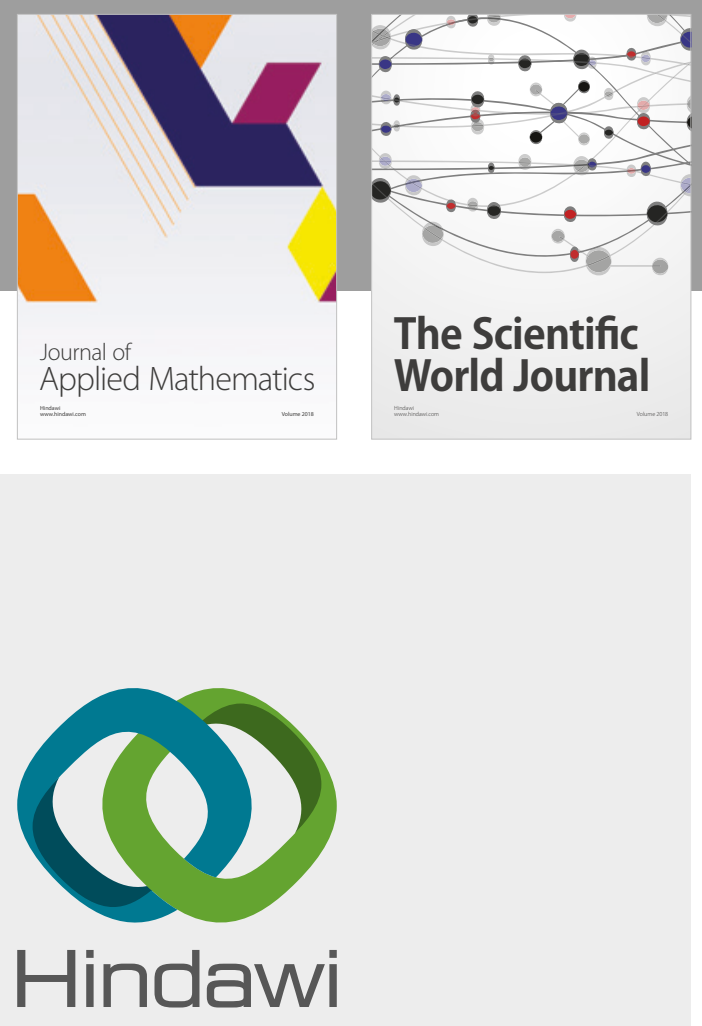

Submit your manuscripts at

www.hindawi.com

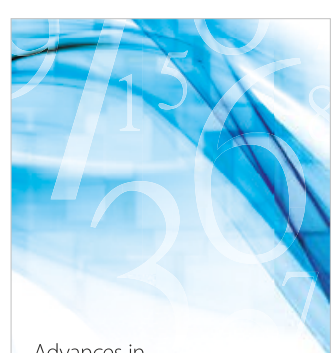

Advances in
Numerical Analysis
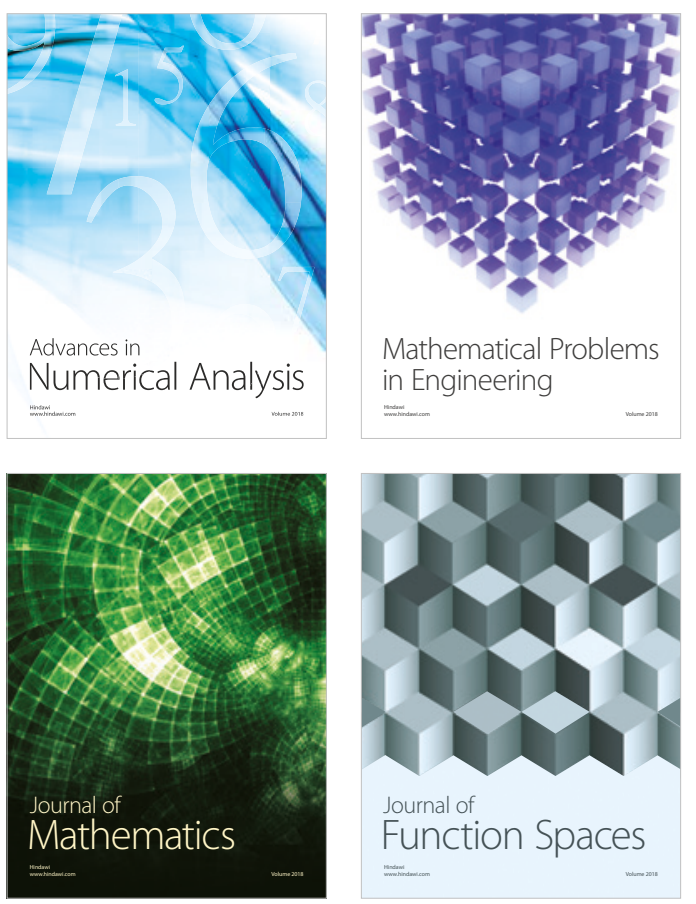

Mathematical Problems in Engineering

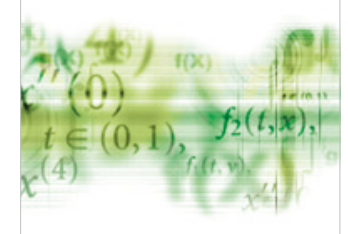

International Journal of

Differential Equations

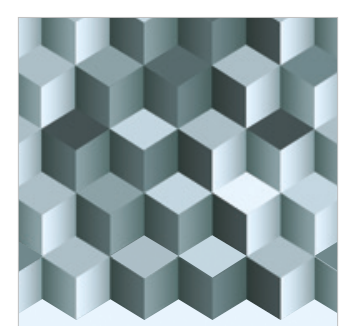

Journal of

Function Spaces

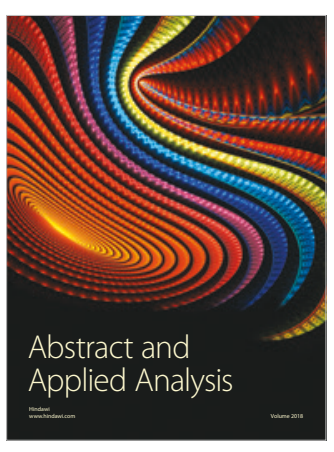

The Scientific

World Journal

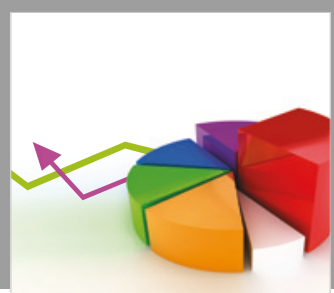

Journal of

Probability and Statistics
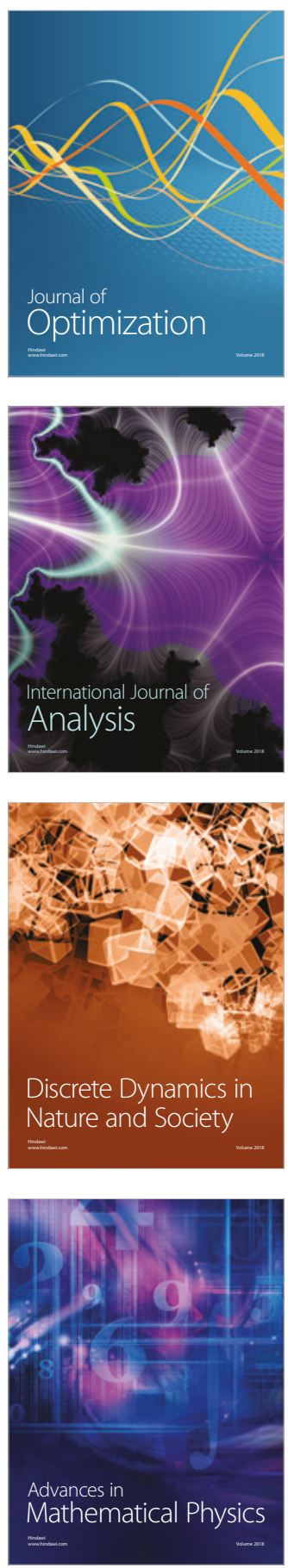